\title{
Monitoring of a reverse cement job in a high-temperature geothermal environment
}

\author{
Martin P. Lipus ${ }^{1 *}{ }^{\mathbb{C}}$, Thomas Reinsch ${ }^{1,2} \mathbb{D}$, Tobias B. Weisenberger ${ }^{3}$, Steinar Kragset ${ }^{4}$, Ari Stefánsson ${ }^{5}$ \\ and Sigurdur G. Bogason 6
}

${ }^{*}$ Correspondence: mlipus@gfz-potsdam.de ${ }^{1}$ GFZ German Research Centre for Geosciences, Telegrafenberg, 14473 Potsdam, Germany Full list of author information is available at the end of the article

\begin{abstract}
Cementing operations in wellbores, especially for long casings, are often challenging and prone to deficiencies when not properly planned and executed. While exploring for and exploiting of geothermal resources at temperatures above the critical point of water was attempted in different drilling projects in recent years, the well design, and especially the procedure to run and cement long production casings became a key challenge for drilling engineers. For the first time, a reverse cementing job for a $2.97 \mathrm{~km}$ long production casing in a high-temperature geothermal well could be monitored and analyzed using a combination of permanently installed distributed fiber optic and electronic sensors as well as conventional well logging equipment. Data from the permanently installed sensors were used to monitor and evaluate the cementation process as well as the onset of the cement hydration. Based on the data, the understanding of downhole fluid dynamics during cementation could be improved. Our analysis suggests that the cement was diluted during cement placement and partly lost into the formation. These findings can help to better prepare for future drilling ventures under similar downhole conditions.
\end{abstract}

Keywords: Well cementing, Well integrity, Distributed temperature sensing (DTS), Iceland deep drilling project (IDDP-2)

\section{Introduction}

Cementing a casing string is considered one of the most important operations during the construction of a wellbore (Allouche et al. 2006). Not only does the cement prevent short mixing of fluids from different geological formations, it also gives the well construction its required strength to withstand hostile downhole environments. The completion of deep geothermal wells is challenging because of high pressure and temperature at depth and high radial thermal gradient during load changes (Teodoriu and Falcone 2009). High-temperature geothermal wells in Iceland are typically equipped with a conductor casing, a surface casing, an anchor casing, a production casing and a perforated liner. Such casings are typically cemented to the surface to withstand the extreme thermal and mechanical loads (except the liner which is usually just hanging). The practice to cement the entire casing gives rise to technical challenges during cementation of exceptionally long casings due to the differential pressure conditions

(c) The Author(s) 2021. This article is licensed under a Creative Commons Attribution 4.0 International License, which permits use, sharing adaptation, distribution and reproduction in any medium or format, as long as you give appropriate credit to the original author(s) and the source, provide a link to the Creative Commons licence, and indicate if changes were made. The images or other third party material in this article are included in the article's Creative Commons licence, unless indicated otherwise in a credit line to the material. If material is not included in the article's Creative Commons licence and your intended use is not permitted by statutory regulation or exceeds the permitted use, you will need to obtain permission directly from the copyright holder. To view a copy of this licence, visit http://creativeco mmons.org/licenses/by/4.0/. 
both at the casing and the formation (collapse and fracturing). The completion engineer must therefore be very selective in determining the correct cement weight (Salim and Amani 2012). Long cemented production casings (close to $3 \mathrm{~km}$ ) were introduced in the high-temperature geothermal industry to explore for superhot or supercritical geothermal fluids downhole, e.g., in the Descramble project (Bertani et al. 2018) and IDDP-1 (Pálsson et al. 2014). Long cemented sections require dedicated cementing strategies, e.g., reverse cementing in Iceland (RN-15/DEEPEGS/IDDP-2) (Fridleifsson et al. 2016) or two-stage cementation using a tieback in Italy (Venelle-2). The setting behavior of cement slurry is affected by the temperature occurring in the borehole and the cement additives. Depending on the cementing length and environment, a specific cement mixture is designed which allows for optimal pumping and a quick cement hardening onset once the cement is in place. A higher temperature reduces the setting time so the cement sets quicker compared to a cooler well temperature. A higher temperature also affects the cement rheology. The plastic viscosity and yield point decreases with increasing temperature (Ravi and Sutton 1990). Earlier, such resource conditions were encountered (partly accidentally) and posed an insurmountable barrier to successfully complete and test such wells (Bertini et al. 1980; Fridleifsson et al. 2014; Reinsch et al. 2017).

Cementing operations are typically poorly monitored and largely rely on measurements of density, volumetric flow rate and pressure, temperature at the surface. Downhole displacement processes are assessed during post job cement evaluation, either by cement bond-logs (CBL) or an ultra-sonic imager tool (USIT).

Fiber optic sensing technology allows to measure a variety of downhole parameters passively in the borehole in real-time. In previous studies, distributed temperature sensing (DTS) data from hot and cold water injection have been used to determine the location of permeable zones (fractures) and showed the propagation of the injected fluids into the formation (Hurtig et al. 1994). DTS was used to study thermal properties of the lithologies in a borehole (Förster et al. 1997; Henninges et al. 2005) and to monitor reservoir temperatures (Carnahan et al. 1999; Patterson et al. 2017). Moreover, fiber optic distributed data were used to perform cement job evaluations and wellbore integrity analysis during and after production tests (Pearce et al. 2009; Earles et al. 2011; Koelman et al. 2012; Reinsch et al. 2013; Bücker and Grosswig 2017; Lipus and Reinsch 2018; Raab et al. 2019). In this work, we report on DTS data acquired during cement placement along a permanently installed fiber optic cable.

With depth reference to the ground surface, the fiber optic cable was installed down to $832 \mathrm{~m}$ behind the $95 / 8$ " (445-2932 $\mathrm{m})$ and $97 / 8$ " (0-445 m) production casing in well RN-15/DEEPEGS/IDDP-2 in the Reykjanes geothermal field, south-west Iceland (Fig. 1). In addition to the fiber optic cable, eight thermocouples and one combined pressure gauge and thermocouple were installed. Table 1 lists the different installed sensors. For the first time, downhole data from a reverse cementing job in a geothermal well could be analyzed and hydraulic processes during the operation could be described.

\section{Well drilling and completion}

The depth information throughout the manuscript are referenced to Thor rig floor ( 9 $\mathrm{m}$ above surface), unless it is explicitly mentioned that the depth reference is to surface. The official well naming RN-15/DEEPEGS/IDDP-2 is replaced by "the well". 


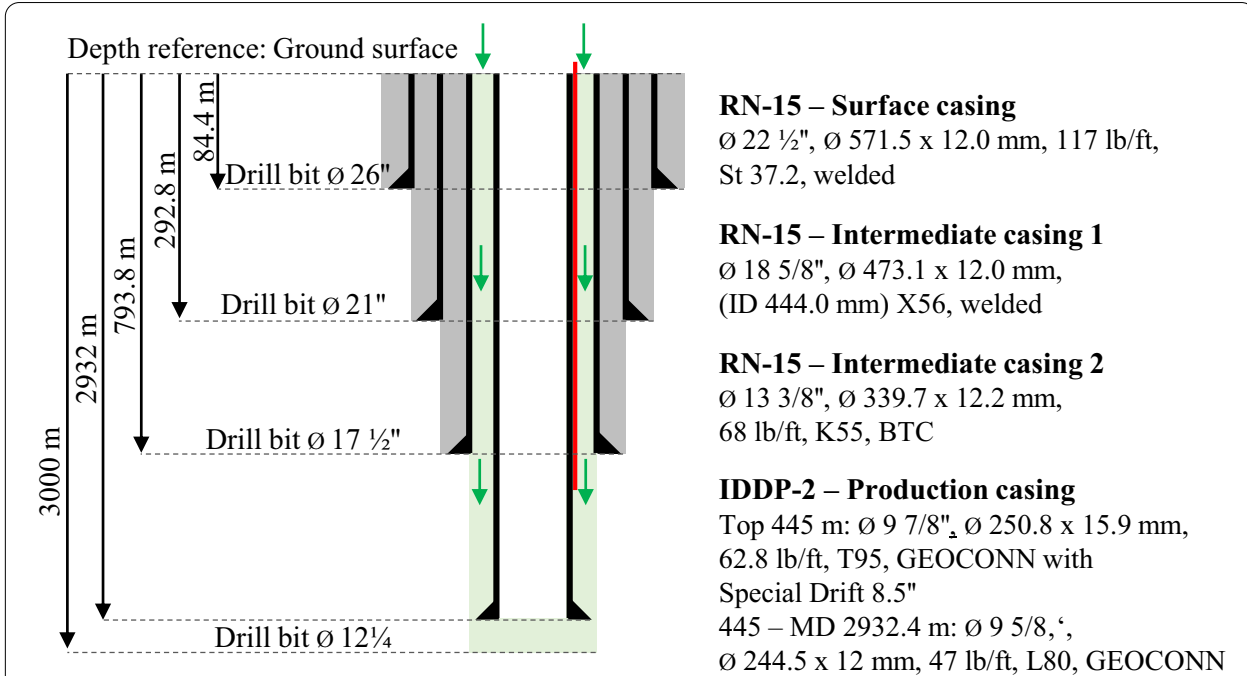

Fig. 1 Design of the well and landing depth of fiber optic cable (red line). The cementing section is displayed in green color

Table 1 List of downhole sensors installed in RN-15/DEEPEGS/IDDP-2 with depth reference to surface

\begin{tabular}{lc}
\hline Sensor & $\begin{array}{c}\text { Measured } \\
\text { depth (m) }\end{array}$ \\
\hline Thermocouple No. 1 & 2632 \\
Thermocouple No. 2 & 2332 \\
Thermocouple No. 3 & 2132 \\
Thermocouple No. 4 & 1832 \\
Thermocouple No. 5 & 1532 \\
Thermocouple No. 6 & 932 \\
Thermocouple No. 7 & 632 \\
Thermocouple No. 8 & 332 \\
Pressure gauge and TC & 1232 \\
Fiber optic cable & 832 \\
\hline
\end{tabular}

The well is located in the Reykjanes geothermal field in south-west Iceland (Fridleifsson et al. 2017). An already existing well (RN-15) in the geothermal field, which was drilled in 2004, was selected as the target well for the DEEPEGS/IDDP-2 project. The well was completed with a $133 / 8$ " production casing cemented from $0-794 \mathrm{~m}$ and a 12 1/4" open hole drilled to $2500 \mathrm{~m}$ (from surface) (Jónsson et al. 2010). The well was left as an open hole without being supported by, i.e., a perforated liner. The activity for the deepening of the well started with drilling the well vertically to $2750 \mathrm{~m}$. Below that, the well was drilled directionally to the south-west $\left(16^{\circ}\right.$ planned inclination) to a measured depth of $3000 \mathrm{~m}$. Within the interval of the production casing, several lost circulation zones were observed. The well was drilled blind (from RN-15 to $3000 \mathrm{~m}$ ) with a total loss of circulation without cuttings being retrieved at surface (Stefánsson et al. 2017). A cement job was performed to seal a zone near the KOP and multiple cycles of cleaning and reaming were performed. Polymer pills and bentonite were circulated in the well 
before installing the $97 / 8$ " and $95 / 8$ " casing. During running the casing, the integrity of the TCs as well as the fiber optic cable was regularly assessed after each joint. As the casing string reached a depth of $2932 \mathrm{~m}$ (from surface), a damage on TC3 was detected. Instead of running the casing to TD, it was decided to land the casing at this location. In the next phase, the well was drilled with an $81 / 2$ " bit from 3000-4626 m. Additional $33 \mathrm{~m}$ were drilled with a 6 " bit and coring bit to a measured depth of $4659 \mathrm{~m}$. After drilling was finished, a $31 / 2$ " drill string was inserted into the well to thermally enhance the permeability in the lower part of the reservoir using cold fluid injection. During retrieval of the drill string, it was observed that the production casing was severely damaged between 2307 and $2380 \mathrm{~m}$ close to one of the main former feed zone for production well RN-15 (IDDP 2018).

\section{Cementing operation}

Prior to the cementing operation, it was known that there were loss zones near $2360 \mathrm{~m}$ depth and that the water table was at 600-800 m during pumping. Other older loss zones were also known. The following steps were planned for the reverse cementing operation of the $95 / 8$ " and the $97 / 8$ " casing:

- Start to batch mix $40 \mathrm{~m}^{3}$ at $1910 \mathrm{~kg} / \mathrm{m}^{3}$ on 4 cementing trucks on location.

- Fill lines and pressure test to 350 bar.

- Start cementing with two units for the first $80 \mathrm{~m}^{3}$ at $1.6 \mathrm{~m}^{3} / \mathrm{min}$.

- Shut in valve on casing swage after $75 \mathrm{~m}^{3}$ are pumped.

- Reduce pumping rate to $0.5 \mathrm{~m}^{3} / \mathrm{min}$ and pump $25 \mathrm{~m}^{3}$.

- Reduce pumping rate to $0.25 \mathrm{~m}^{3} / \mathrm{min}$.

- Stop pumping after $132 \mathrm{~m}^{3}$ and a slurry density between $1920 \mathrm{~kg} / \mathrm{m}^{3}$ to $1970 \mathrm{~kg} / \mathrm{m}^{3}$.

The cementing slurry is API G cement with $40 \%$ silica flour and retarder in the first 127 ton. The laboratory analysis of the cement slurry can be found in the Appendix in Tables 4 and 5 . The remaining cement slurry was without retarder. Cementing of the casing in well started around 22:45 on September 5th by pumping cement slurry through the kill-line from the top of the well. At 02:45 on the morning of September 6th, $132 \mathrm{~m}^{3}$ of cement slurry were already pumped into the annulus and the pressure on the casing was noted $15.6 \mathrm{psi}(1.07 \mathrm{bar})$. After pumping the $132 \mathrm{~m}^{3}$, the annulus needed to be filled up. So, after $6 \mathrm{~h}$, the annulus was filled up with $17.3 \mathrm{~m}^{3}$ cement slurry with a density of $1970 \mathrm{~kg} / \mathrm{m}^{3}$ at a rate of $0.34 \mathrm{~m}^{3} / \mathrm{min}$. The cementing operation was finished on September 6th about 10:30 (Stefánsson et al. 2017, 2020).

\section{Cement job evaluation}

Two consecutive cement-bond logs (CBL) were carried out in order to monitor the evolution of the cement bonding of the casing in the well. Previous to each CBL a temperature profile was logged, both to get a temperature profile, and to see if conditions in the well were within the CBL-tool's limitations $\left(<150{ }^{\circ} \mathrm{C}\right)$. Additionally, a pressure tool was run simultaneously together with the temperature tool before the first CBL log was carried out. Figure 2 shows the pressure (black) and temperature profile (blue) logged on September 6th at 15:00 and on September 7th at 14:04 (red). 


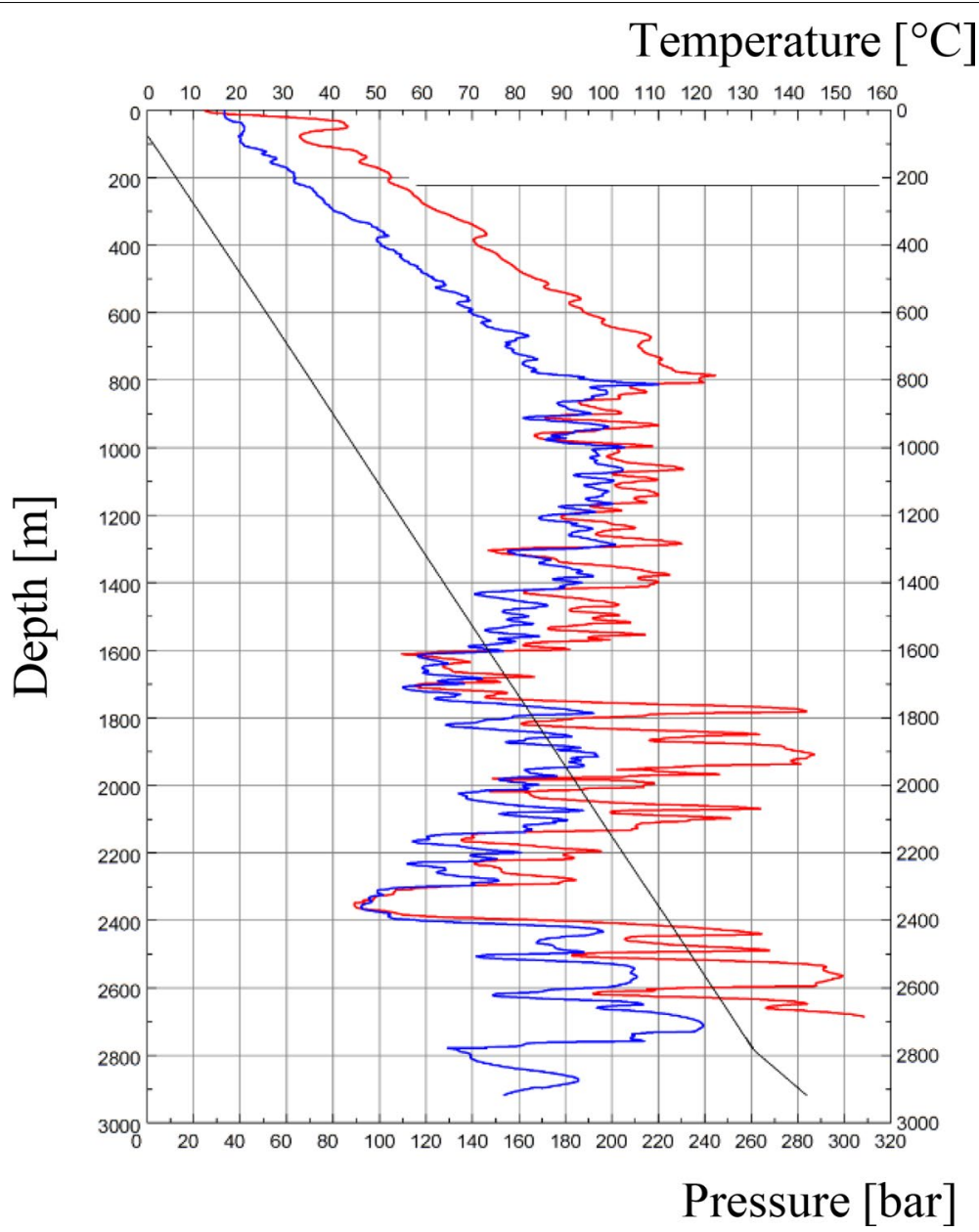

Fig. 2 Temperature (blue line) and pressure (black line) logged on September 6 th at 15:00, $Q=0 \mathrm{l} / \mathrm{s}$. Temperature (red line) logged on September 7th at 14:04 after completion of cementing job. Cement bond logs were carried out subsequently. Depth reference is Thor rig floor ( $9.0 \mathrm{~m}$ above surface). Figure modified from (Stefánsson et al. 2020)

With respect to the pressure log, the water table inside the casing can be determined at $75 \mathrm{~m}$. Below, the pressure gradually increases following the hydrostatic profile down to $2780 \mathrm{~m}$. From there a slight decrease in the slope is observed where the tool probably entered the zone of cement slurry which fills the lowermost section of the well. The measured slope indicates a density of $1730 \mathrm{~kg} / \mathrm{m}^{3}$. This is lower than the potential slope for a cement slurry static profile $\left(1940 \mathrm{~kg} / \mathrm{m}^{3}\right.$, i.e., the used density of the pumped down cement slurry).

The temperature curves exhibit a gradual increase in the uppermost $800 \mathrm{~m}$ with a constant offset of about $20-25{ }^{\circ} \mathrm{C}$. From $800-1600 \mathrm{~m}$, the temperatures slightly decrease again. Below $1600 \mathrm{~m}$ temperatures strongly fluctuate for both logs in a similar way. Prominent cooling zones can be seen at 1600-1700 m and 2300-2400 m where most of the drilling fluid flowed out of the well during drilling. Some minor cooling zones, as part of the newly drilled section of the well $(>2500 \mathrm{~m}$ ), are found at 2505, 2620, 2778 and $2920 \mathrm{~m}$, though they rather indicate zones of higher permeability than feed zones. 
The first CBL was run on September 6th at 19:40, approximately $10 \mathrm{~h}$ after cementing was finished and 22 hours after cementing was started. The second CBL was run on September 7th at 17:35. The first CBL was run to $2778 \mathrm{~m}$ depth. The second CBL was terminated at a depth of $2500 \mathrm{~m}$ because temperatures were reaching $150{ }^{\circ} \mathrm{C}$ below that depth. The logs can be found in Fig. 3. Essentially for both cement bond logs, the recorded signal does not indicate a good cement bond. This may have different causes: e.g., the cement did not yet harden enough, or there is no cement at all. Starting with the first CBL, in the uppermost $800 \mathrm{~m}$ (where the outer casing is located) a good cement bond can only be seen at 780-850 m. Nevertheless, an overall low first amplitude may suggest a proper bonding except for some weak zones at 760-770, 815 and 850-860 m. It can be concluded that, throughout the most part of the uppermost casing, the cement bond is reasonably good. From 860-1400 $\mathrm{m}$ the cement bond is fairly good but a poor bond is observed from $895-925 \mathrm{~m}$ and from $970-980 \mathrm{~m}$. A dramatic change in amplitudes can be observed below $1400 \mathrm{~m}$. From there on, the cement bond (or hardening) seems generally weak. Thus, from 1400 to $2370 \mathrm{~m}$, a non-uniform and poor cement bond is detected and the casing collars are readily seen in that interval. Previous temperature logs also infer a feed zone of good permeability around $2370 \mathrm{~m}$ depth. From 2370 to $2774 \mathrm{~m}$ the cement bonding conditions are poor and the CBL is indicative for

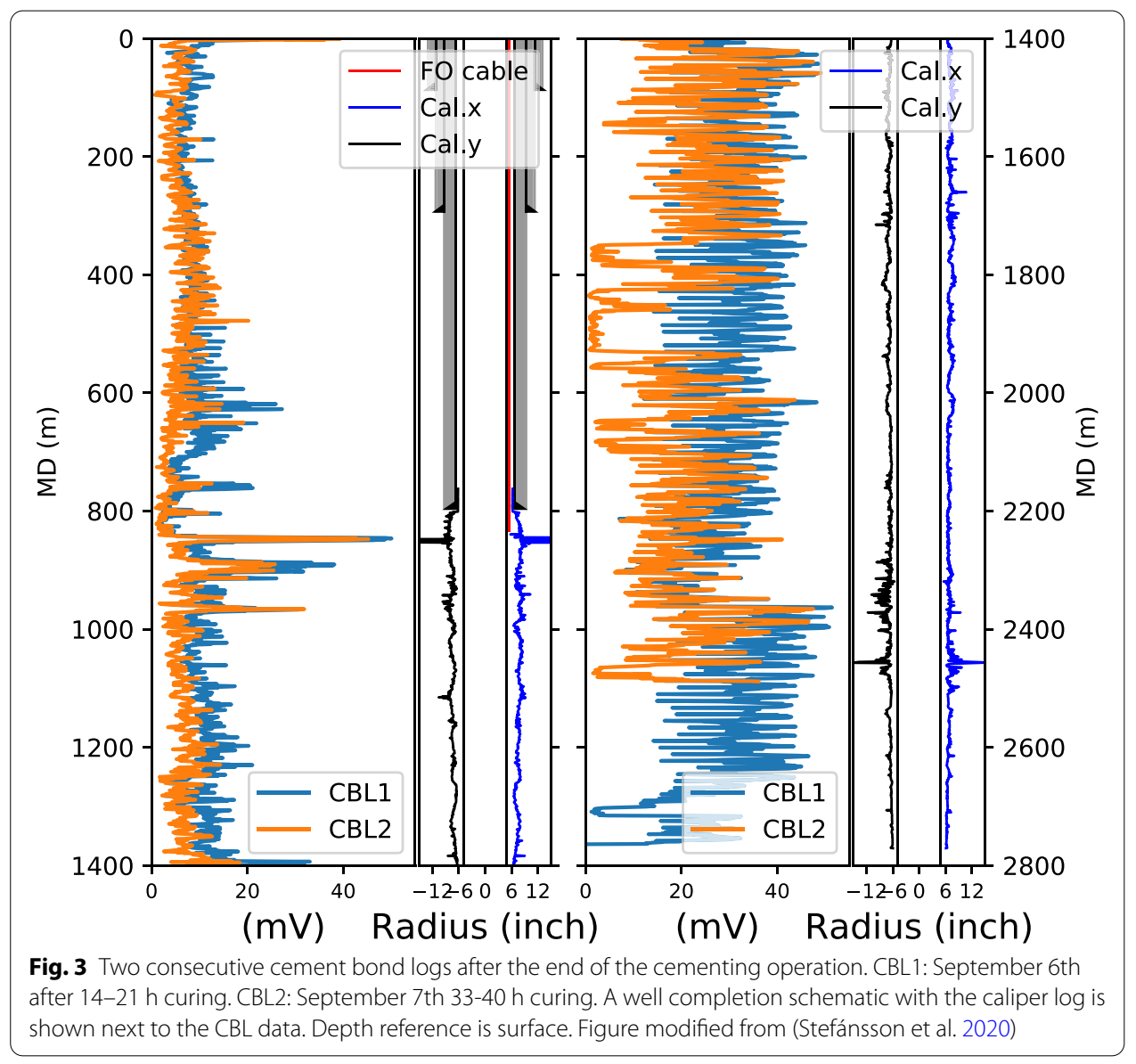


a nearly free pipe amplitude (unbonded casing). An exception is shown between 2710 and $2725 \mathrm{~m}$ indicating a good bond condition. The first CBL was limited to a depth of $2774 \mathrm{~m}$. Below, the top of cementing slurry in the well was reached which is also indicated by the pressure log. The second CBL indicates some minor improvements in the cement bond especially in the uppermost part $(<800 \mathrm{~m})$, but is still rather weak below $1400 \mathrm{~m}$ depth. In general, the cement bond is slightly better than in the first CBL. Comparing the first and second $\mathrm{CBL}$, some obvious changes can be observed showing more zones with improved bonding for the second CBL and casing collars not as clearly visible as in the first CBL.

\section{Cement droplet velocities in the annulus}

Because the water table is at around $700 \mathrm{~m}$ before cementing starts, we assume the following model for the falling annular cement droplets during the reverse cementing operation. We assume that the wall friction of the fluid is balancing the hydrostatic pressure gradient. This requires the fluid to maintain contact with the walls as the blobs are falling down the annulus, and for simplicity, only single-phase flow is considered while countercurrent flow of air escaping upwards is neglected. If wall contact is not maintained, the blobs would accelerate indefinitely unless two-phase effects are accounted for.

In the following, the annulus is assumed to be perfectly concentric. While water is a Newtonian fluid, the rheology of the cement slurries can typically be fitted to a Herschel-Bulkley model,

$$
\tau=\tau_{y}+K \dot{\gamma}^{n} \text {,for } \tau>\tau_{y},
$$

where $\tau$ is the shear stress, $\dot{\gamma}$ the shear rate and $\tau_{y}, K$ and $n$ are the yield stress, consistency index and flow index, respectively. By modeling the annulus as a slot (Founargiotakis et al. 2008), formulated a method to estimate the velocity of Herschel-Bulkley fluids in laminar, transitional and turbulent flow regimes. If the blobs are spanning the annular region and the axial lengths of each blob is sufficiently long, this method can be used to estimate the velocity of the falling fluid.

Following their approach, the flow velocity $\mathrm{V}$ in laminar flow is given by

$$
V=\left(\frac{d p / d L}{K}\right)^{m} \frac{(h / 2)^{m+1}(1-\xi)^{m+1}(\xi+m+1)}{(m+1)(m+2)},
$$

where $\mathrm{m}=1 / \mathrm{n}, \mathrm{h}$ is the annulus gap. The pressure gradient is the hydrostatic pressure gradient,

$$
d p / d L=\rho g
$$

where $\rho$ is the density and g the gravitational acceleration. The dimensionless shear stress $\xi$ can then be calculated as

$$
\xi=\frac{2 \tau_{y}}{h d p / d L} .
$$

To justify an assumption that the flow is laminar, the generalized Reynolds number needs to be below the transitional range, as outlined in Founargiotakis et al. 2008. They 
provide a numerical procedure for predicting the velocity for transitional and turbulent flow via estimates for the friction factor, which is also used in the calculation below.

\section{Methods}

The fiber optic cable was installed behind the production casing ( $97 / 8$ " and $95 / 8$ ") of the well. A schematic of the cable design is presented in Fig. 4. The cable contains one multi-mode (MM) fiber and one single-mode (SM) fiber. The two fibers are located inside a stain-less steel tube. To reduce degradation of the optical fibers at elevated temperature, the tube is filled with dry nitrogen. Another resilient steel sheath covers the outside of the cable, giving the cable a nominal overall diameter of $6.35 \mathrm{~mm}$. The maximum operating temperature is $300{ }^{\circ} \mathrm{C}$. All cables (thermocouples and fiber optic cable) were protected using three clamps per joint. Two different types of clamps were installed, two mid-joint clamps at $1 / 3$ and $2 / 3$ of each pipe and an over-collar clamp that also centralized the casing. Within the $133 / 8$ " casing, the former production casing of RN-15, only a single mid-joint clamp was used. Using OTDR measurements, the fiber health was confirmed after each joint during run-in-hole. To ensure accurate temperature readings, $100 \mathrm{~m}$ of the fiber optic cable was fully submerged within an ice bath to correct for an eventual offset in the temperature data. A reference temperature gauge (VEMCO Minilog-II-T) was used to verify the constant temperature of the ice bath. Ice spray was used to locate individual traces along the optical cable. A second temperature logger was placed in the measurement container at the well site to monitor the temperature in vicinity of the DTS system. A third logger was placed on the outside of the reference bath to record the ambient temperatures.

\section{Distributed temperature sensing (DTS)}

Fiber optic distributed temperature sensing, or DTS, describes the technology of using each location of a glass fiber as a sensor for temperature (Hartog 1983). This is done by coupling optical pulses with a wavelength of $1064 \mathrm{~nm}$ into a glass fiber and measuring the backscattered light as a function of time. Given the two-way travel time and the speed of light in the glass fiber, a physical origin of the backscattering location can be determined. Different methods are available for DTS measurements. In this study, we use a system that is based on Raman backscatter.

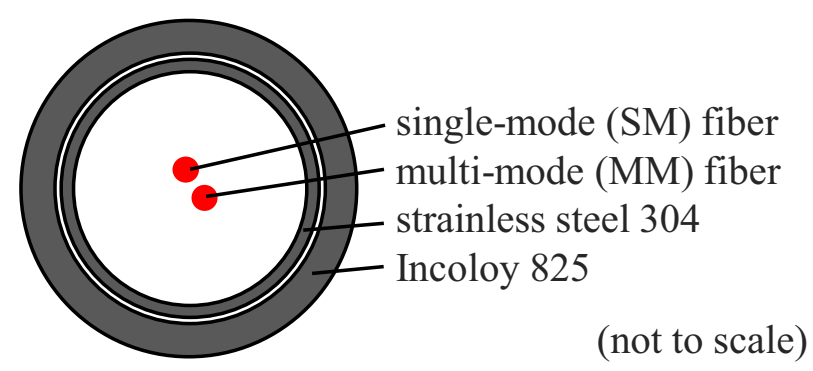

Fig. 4 Fiber optic cable schematic 
Table 2 DTS measurement overview

\begin{tabular}{ll}
\hline Number of measurements & 8470 \\
Temporal resolution (s) & 38 \\
Spatial resolution $(\mathrm{m})$ & 0.5 \\
Start measurement & $03.09 .201621: 00$ \\
End measurement & $07.09 .201610: 30$ \\
\hline
\end{tabular}

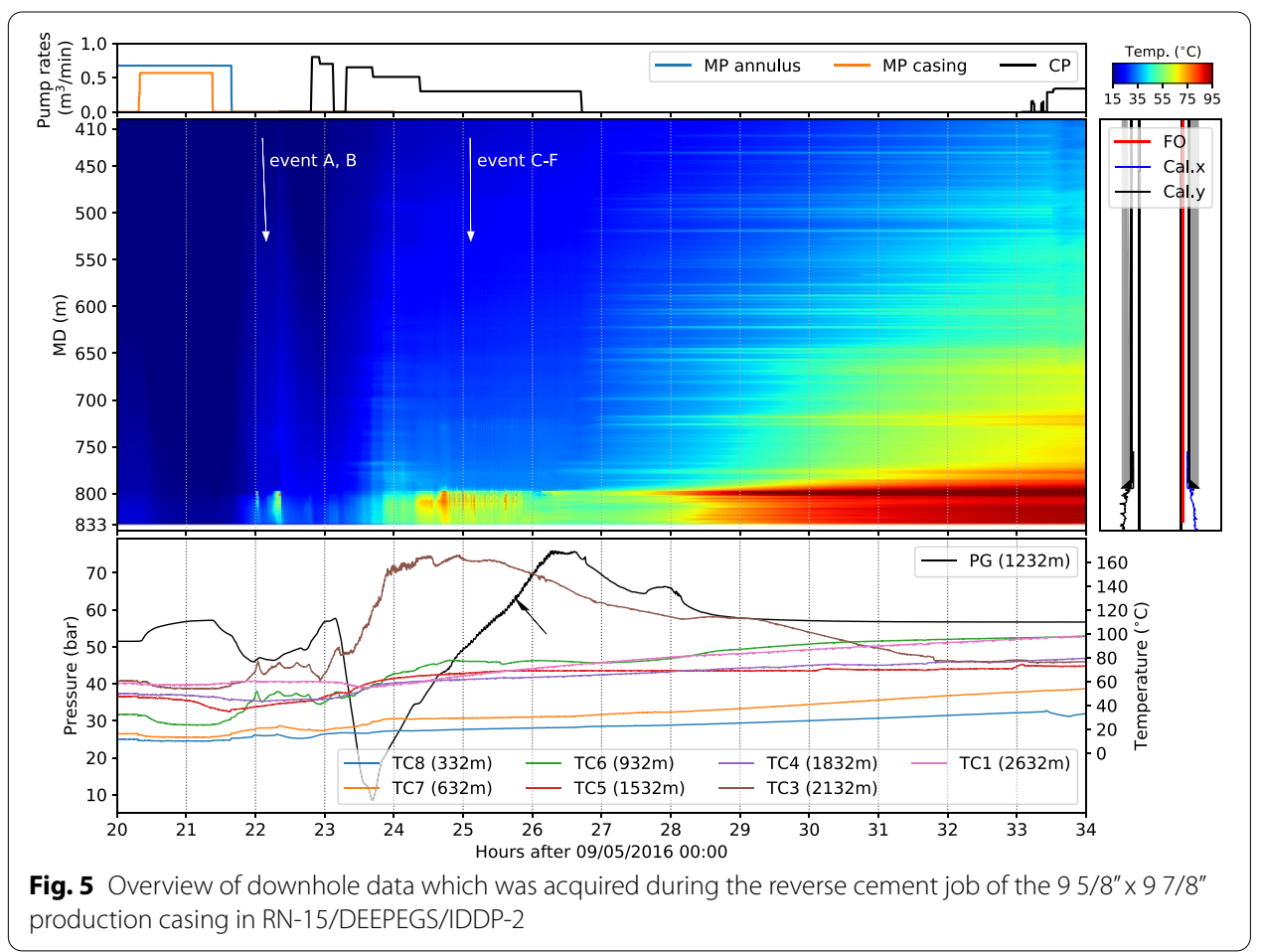

\section{Measurement overview}

The interrogation unit for distributed temperature sensing (DTS) was installed on September 3rd and continuously measured until September 7th. A total number of 8470 temperature profiles were recorded. The fiber optic cable covers the interval from surface to $832 \mathrm{~m}$ depth. A temperature profile was acquired every $38 \mathrm{~s}$. The spatial resolution was $0.5 \mathrm{~m}$ (Table 2 ).

\section{Results}

Downhole data from pre-cementing observations and the cement pumping are shown first. After that, the analysis of the annular velocity of falling droplets is shown. Figure 5 shows an overview of the DTS temperature readings gathered during the cementation of the $97 / 8$ " and 95/8" production casing together with the flow rates pumped into the casing and/or the annulus as well as the readings of the downhole thermocouples and the downhole pressure gauge. The depth interval in the DTS colormap shows the depth interval from 400-832 m. On the right, a schematic of the well with 
the position of the fiber optic cable is shown together with the borehole geometry from a caliper log.

Figure 6 shows a close-up of the depth interval from 550-832 m. A number of temperature isolines are plotted on top of the colormap to delineate subtle temperature changes along the well column.

\section{Pre-cementing observations}

A pressure of 51.5 bar was measured at the downhole pressure gauge before the start of the cementation. At this time, water was injected into the annulus with a flow rate of $0.672 \mathrm{~m}^{3} / \mathrm{min}$. Given a fresh water column at $20{ }^{\circ} \mathrm{C}$, the water table is estimated at $710 \mathrm{~m}$. The pressure increase from 20:00 to 21:30 is 5.6 bar at an increasing injection rate of $0.567 \mathrm{~m}^{3} / \mathrm{min}$ through the casing. After $21: 30$, both mud pumps (casing and kill-line) were stopped. This shows as a transient pressure decrease from 57 bar to 46 bar. Given the water injection rates and the downhole pressure information, an injectivity index can be calculated for the entire well column. As the pressure approaches $46 \mathrm{bar}$, the temperature at TC6 $(932 \mathrm{~m})$ and TC3 $(2132 \mathrm{~m})$ increases (21:50). In the same time, the DTS data show locally increased temperatures in the open-hole section at $802 \mathrm{~m}$ and $809 \mathrm{~m}$. The DTS temperature increases to above $70{ }^{\circ} \mathrm{C}$ within 5 min and then abruptly decreases back to around $20{ }^{\circ} \mathrm{C}$ upon pressure increase at the pressure gauge. This temperature effect occurs two times, at 22:00 and 22:15. Prior to the abrupt temperature changes below $800 \mathrm{~m}$, we observe a gentle negative temperature anomaly migrating downwards in the annulus. The pressure reading slightly increases until 22:50 by 3 bar. With the increase in pressure, no local DTS temperature peaks are present and the TC6 and TC3 readings remain relatively stable.

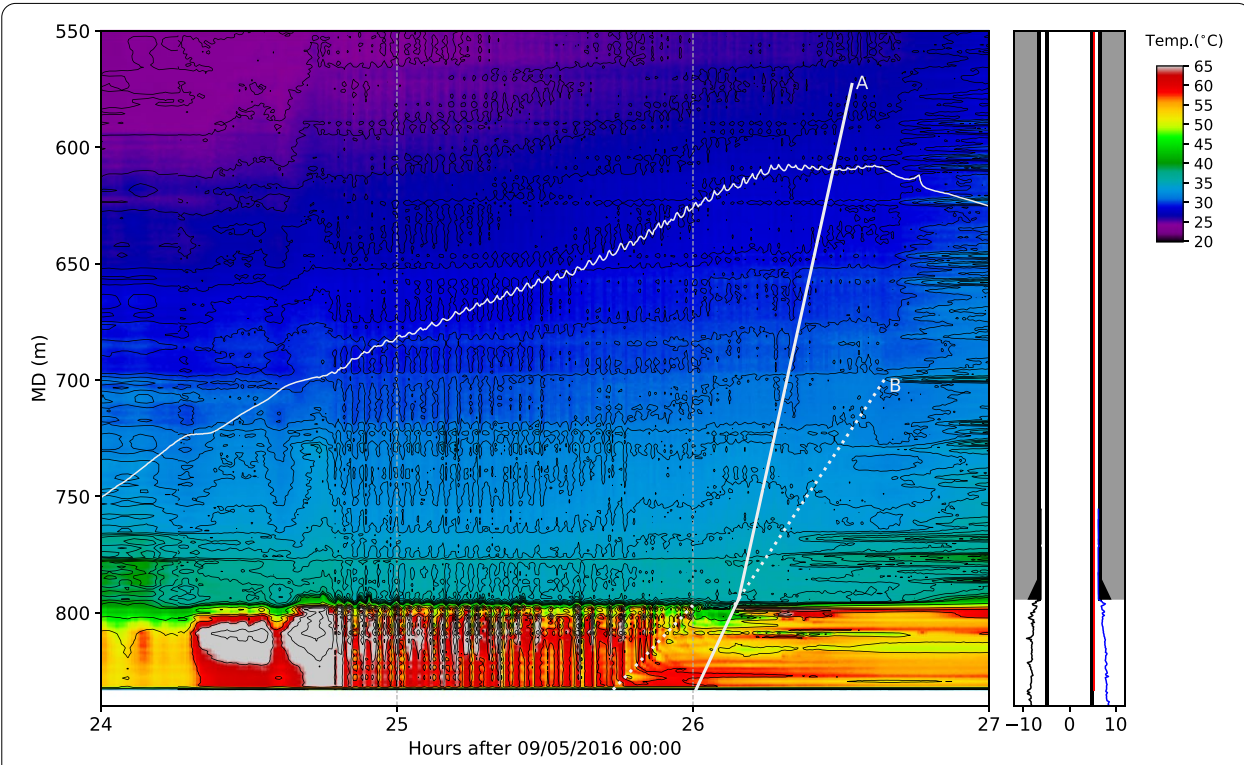

Fig. 6 Close-up of downhole data which was acquired during the reverse cement job of the 95/8" and $97 / 8$ " casing in $\mathrm{RN}-15 / \mathrm{DEEPEGS} / \mathrm{IDDP}-2$. The pressure gauge reading is again displayed in white 


\section{Cement pumping}

At 22:50, the cement pumping starts. The DTS shows a cooling over the entire measurement length. The pressure increases to around 60 bar during the initial phase of cement pumping until 23:10. At the same time the pressure starts to increase, the temperature at TC3 $(2132 \mathrm{~m})$ decreases by $10{ }^{\circ} \mathrm{C}$ until 23:00. The temperature then increases until the end of the initial cement pumping phase at 23:10. From 23:12 onwards, the pressure reading at $1232 \mathrm{~m}$ decreases to 8 bar at 23:40. In the meantime, TC3 (2132 m) shows a rapid increase in temperature from 85 to $163{ }^{\circ} \mathrm{C}$ within $30 \mathrm{~min}$ after the main cementation phase starts at 23:18. With ongoing cement pumping, the pressure increases gradually from 23:40 to 26:20. In the time window from hour 25:00 to 27:00, the pressure gauge reading is superimposed by a wavy pattern (indicated by the black arrow in the bottom subplot in Fig. 5). In the same time, the DTS temperature fluctuates strongly in the open-hole section at 794-832 m (see Figs. 5 and 6). From 25:50 onwards, the vertical columns marked by the DTS isolines are gradually replaced by horizontal lines which rise from the bottom upwards. As this pattern transition (white dotted line "B" in Fig. 6) reaches the shoe of the $133 / 8$ " casing (26:00), the depth interval from 797-805 m cools down for $6 \mathrm{~min}$, before this pattern continues to rise in the cased hole interval. Below $805 \mathrm{~m}$, no thermal perturbation was observed in this time period.

A theoretical model of the location of the TOC was assessed by calculating annular volumes from the caliper log, casing diameters and the pump rate (white solid line "A" in Fig. 6). In the hypothetical case that no loss zones were present in the well, a total volume of approximately $141 \mathrm{~m}^{3}$ of cement slurry would be sufficient to fill the annulus to surface (neglecting any shrinkage of the cement). For comparison, line "A" was delayed along the time axis in Fig. 6 to match the location when line "B" continues to rise in the cased hole interval (26:06). The highest point of line "A" is placed at $573 \mathrm{~m}$. This depth marks the location to which the well can be maximally filled in order to allow the top-up cement volume of $17.3 \mathrm{~m}^{3}$ (which was pumped 6 hours later) to fit into the annulus. Both in the open hole section as well as the cased hole section, the calculated TOC is significantly steeper compared to the transition line picked from DTS data. At the moment where line "A" and line "B" intersect, the pressure gauge at $1232 \mathrm{~m}$ reads 73 bar. After primary cement pumping stops, the pressure at the pressure gauge stabilizes at 57 bar. For the first $80 \mathrm{~m}^{3}$, the standpipe valve was open but after closing the backpressure started to rise and ended at about 2 bar when cementing was halted. The top-up cement job after 33:00 shows a relative cooling of the upper $660 \mathrm{~m}$ of the well and no temperature change below, indicating an immobile cement column. The shallowest thermocouple (TC8) shows a gentle cooling during the top-up cement pumping.

\section{Annular velocities}

The annular fluid velocity from the DTS was determined manually with the help of contour plot (depth over time) displaying isotherms in the well (see Fig. 7). As cold water falls in the relatively warm annulus during water injection, the DTS cable cools down with time and increasing depth. During event A and B (left subplot in Fig. 7), cold water falls along the casing side with the DTS cable attached to it. This shows as a local elevation of the isotherms which propagates downwards in the well with time. 


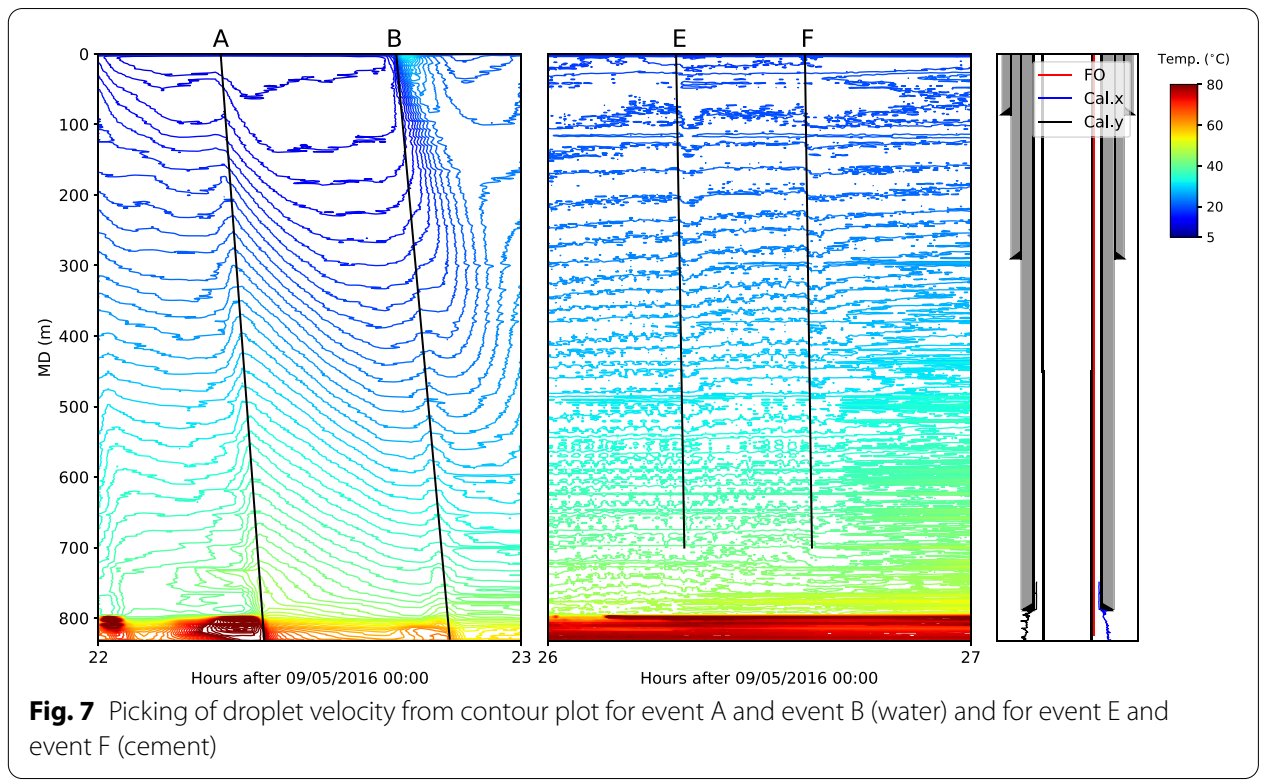

Table 3 Fluid speed in annulus (see events marked in Fig. 5)

\begin{tabular}{lllllll}
\hline Event & Depth start $(\mathbf{m})$ & $\begin{array}{l}\text { Depth } \\
\text { bottom }(\mathbf{m})\end{array}$ & Time start $(\mathbf{s})$ & Time end $(\mathbf{s})$ & Velocity $(\mathbf{m} / \mathbf{s})$ & Comment \\
\hline A & 0 & 829 & 320 & 690 & 2.25 & Water \\
B & 0 & 829 & 1850 & 2305 & 1.83 & \\
C & 300 & 829 & 10405 & 10450 & 11.84 & Cement \\
D & 0 & 829 & 12720 & 12800 & 10.41 & \\
E & 0 & 700 & 14700 & 14770 & 10 & \\
F & 0 & 700 & 15760 & 15820 & 11.66 & \\
\hline
\end{tabular}

Displayed times relative to 22:00 of September 5th

The same approach was chosen to determine the fluid velocity of the cement slurry (right subplot in Fig. 7). The contour plots allow only for a rough velocity estimate because the temperature perturbation of falling cement is rather low and the fluid velocity exceeds the DTS sampling rate of $38 \mathrm{~s}$.

The velocity of the interpreted falling water in the DTS data in Table 3 is an orderof-magnitude greater than the expected bulk flow velocity as calculated from the pump rate, and for the falling cement it is greater by almost two orders-of-magnitude. By adopting the model outlined before, the resulting velocity for the falling cement blobs when assuming laminar flow is $12 \mathrm{~m} / \mathrm{s}$. However, this suggests that the flow is well into the turbulent regime, which adjusts the velocity to $6.4 \mathrm{~m} / \mathrm{s}$ by following the procedure for transitional and turbulent flow. This places the predicted velocity for the cement blobs within the observed order-of-magnitude but lower by about $40 \%$. It should be noted that the models used, assumes the fluid to be continuous, which in our case is a simplification that may result in inaccuracies. For the falling water, the approach predicts $10 \mathrm{~m} / \mathrm{s}$, which is higher than for cement and an order-of-magnitude higher than observed. On the other hand, since the falling water is not associated with DTS temperature fluctuations or the wavy pattern superimposed on the 
pressure gauge as for the falling cement, it is not unlikely that these are two different phenomena and that the modeling approach is less suitable for water.

\section{Discussion}

In the RN-15/DEEPEGS/IDDP-2 well, a reverse cementing operation was performed for the $95 / 8$ " and $97 / 8$ " casing interval. The downhole monitoring data from distributed temperature sensing (DTS), thermocouples and pressure data allow an analysis of the downhole dynamics during the cementing operation. The data provides insight on the (1) assessment of the downhole formation injectivity, (2) falling cement droplets and (3) the impact on the outcome of the cementing operation.

\section{Annular injectivity and static formation pressure}

During the pre-cementing phase, the annular temperature was monitored in combination with the flow rate of the mud pumps into the casing as well as the annulus of the casing. Given the water injection rates and the downhole pressure information, an injectivity index can be calculated for the entire annular well column if hydrostatic equilibrium is assumed between casing and annulus. The assumption of hydrostatic equilibrium is supported by the fact that an open shoe is installed to allow for reverse cementing. The pressure increase $\Delta p$ from 20:00 to 21:30 is 5.6 bar at an additional flow rate of $0.567 \mathrm{~m}^{3} /$ $\min \left(34.02 \mathrm{~m}^{3} / \mathrm{h}\right)$. This gives an estimated injectivity index of $I I=\frac{\dot{q}}{\Delta p}=6.07 \frac{\mathrm{m}^{3}}{\mathrm{~h} \cdot \mathrm{bar}}$ for the open-hole section below the $133 / 8$ " casing shoe. Given this injectivity index and the initial injection flow rate of $0.672 \mathrm{~m}^{3} / \mathrm{min}\left(40.32 \mathrm{~m}^{3} / \mathrm{h}\right)$, we can use the same equation to solve for pressure (5.6 bar). With this, we estimate the static formation pressure to be at $\mathrm{p}=51.5 \mathrm{bar}-5.6 \mathrm{bar}=44.9 \mathrm{bar}$ and the natural water table at $773 \mathrm{~m}$ in the well, assuming a fresh water column of $20{ }^{\circ} \mathrm{C}$.

When the mud pumps were stopped at about 21:45, the annular pressure decreased to about 46 bar at the pressure gauge, close to the estimated formation pressure. The annular temperature at a depth of $800 \mathrm{~m}$ increased significantly. As the temperature of the annular fluid is lower than the formation temperature, the density of the annular fluid is higher compared to the density of the formation fluid. Schematic profiles of pressure and fluid density for the depth interval above the pressure gauge before and after fluid injection are depicted in Fig. 8. The cooler and denser fluid column might cause underbalanced conditions in the annulus and possibly a local inflow of warmer formation fluid. Contemptuously, at the depth of thermocouples TC6 (932 m) and TC3 (2132 m) a similar temperature increase occurred, indicating a thermal anomaly likely caused by an interaction with formation fluid. From the observed temperature anomalies, we interpret underbalanced conditions down to TC3. In the time window between the stopping of both mud pumps and start of cementation, the pressure slightly increases by 3 bar indicating a heating up of annular fluid and an increase of the water table in the well. However, we observe a negative temperature anomaly, indicating a fluid flow down the annulus that cools the well along the entire monitored well column and which is especially prominent below $800 \mathrm{~m}$. The volume is unknown as there is no flow documented in the rig log. This might be the more likely reason for the pressure increase prior to the onset of cement pumping at 22:50. The complete picture of the underlying hydraulic process cannot be resolved by the limited amount of information available. 

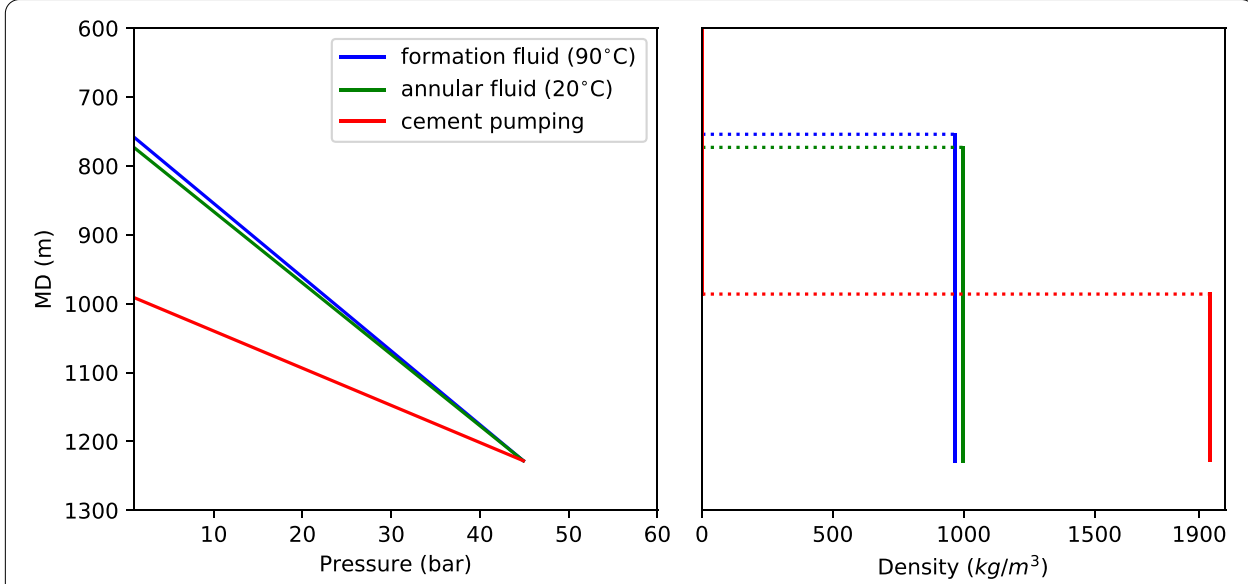

Fig. 8 Simplified representation of the pressure gradient in the well at different phases of the cementing operation

\section{Analysis of cement pumping and velocity of free-falling cement}

After the initial phase on cement pumping into the annulus (from 22:50 to 23:10), the annular pressure drops to 8 bar at the pressure gauge, indicating that (a) the flow rate of the cement is not sufficient to build up a homogeneous cement plug injected into the annulus and (b) cement is flowing to below the pressure gauge. During pumping into the annulus, the cement column drives down the fluid column and counteracts the reservoir pressure. Due to its higher density, the TOC falls below the initial water table creating underbalanced conditions in the upper part of the annulus indicated by the pressure drop seen on the pressure gauge. A pressure reading of 8 bar at $1232 \mathrm{~m}$ can mean that the TOC is located at $1190 \mathrm{~m}$ at 23:50, given a cement slurry density of $1940 \mathrm{~kg} / \mathrm{m}^{3}$ and assuming all annular water is displaced below the depth of the pressure gauge. The subsequent pressure increase (until 26:40) can be explained by a rising TOC above the pressure gauge. At the estimated static formation pressure of $44.9 \mathrm{bar}$, the TOC would be located at a depth of $996 \mathrm{~m}$ given the initial slurry density (see Fig. 8).

In the DTS data, we observed a transition from a vertical pattern to a horizontal pattern which rises from bottom to top from 25:45 onwards (line "B" in Fig. 6). We interpret this interface as the location of the TOC. According to our understanding, the vertical pattern was created by cold falling individual cement blobs into the annulus while in the mean time, relatively hot formation fluid from the surrounding formation intersects the well. Once a continuous cement column formed in the well, a horizontal pattern in the DTS formed because no falling cement blobs occurred any more and the feed zone below the 13 3/8" casing shoe were partly filled with cement slurry. If we follow our interpretation that line "B" marks the location of the TOC, we can say that the TOC reaches the shoe of the $133 / 8$ " at 26:00 and that it continues to rise in the cased hole interval from 26:06 onwards. In the $6 \mathrm{~min}$ in between, we observe a cooling in the depth interval from 795 to $806 \mathrm{~m}$. This might indicate that a part of the cold cement accumulated in the formation just below the shoe of the $133 / 8$ " casing. Giving the time (6 min) and the cement pumping rate $\left(0.3 \mathrm{~m}^{3} / \mathrm{min}\right)$, an estimated volume of $1.8 \mathrm{~m}^{3}$ might be accumulated and possibly lost into the formation. At 26:06, the average cement slurry density $\rho$ in the 
interval between the casing shoe and the pressure gauge can be calculated according to $\rho=p /(g \cdot h)=\left(73 \cdot 10^{5} \mathrm{~Pa}\right) /\left(9.81 \mathrm{~m} / \mathrm{s}^{2} \cdot(1232 \mathrm{~m}-794 \mathrm{~m})\right)=1699 \mathrm{~kg} / \mathrm{m}^{3}$. The pump density from the cement report states an initial cement density of $1940 \mathrm{~kg} / \mathrm{m}^{3}$. The density differences could mean that the cement slurry was diluted by $34 \%$ of formation water. The calculated density of $1699 \mathrm{~kg} / \mathrm{m}^{3}$ is close to the density observed inside the casing during pressure and temperature logging after the end of cementation $(1730 \mathrm{~kg} /$ $\left.\mathrm{m}^{3}\right)$.

Following line " $\mathrm{B}$ " to the end of the primary cementing phase (26:45), we interpret that a depth of about $700 \mathrm{~m}$ is reached in the well. In comparison, the thermal perturbation observed in the DTS data during the top-up cement job was observed down to $660 \mathrm{~m}$ and the volumetric calculation shows that a top-up cement slurry volume of $17.3 \mathrm{~m}^{3}$ should have allowed to fill an annular volume from rig floor down to $573 \mathrm{~m}$. The discrepancy between 700 and $660 \mathrm{~m}$ can be partly explained by remaining cement slurry which is still sinking in the annulus just after stopping of the pumps and the inaccurate estimate of the TOC as the thermal anomaly caused by the cement is small. This is also shown by the DTS measurements in the time from 27:00 until the top-up cementing operation. We measured latent heat from cement hydration up to a depth of around $300 \mathrm{~m}$ in the well, indicating that some cement has set at the casing wall and at the fiber optic cable. This is also the reason, why the $17.3 \mathrm{~m}^{3}$ of cement slurry are sufficient to topup the annulus while measuring the thermal perturbation down to $660 \mathrm{~m}$.

Contradictory to the visual TOC assessment of line "B" is the fact, that the calculated TOC (line " $\mathrm{A}$ ") is much steeper for both the open-hole and cased hole section. In the openhole section, line "A" shows $4.5 \mathrm{~m} / \mathrm{min}$ (line "B" is $2.0 \mathrm{~m} / \mathrm{min}$ ) and in the cased hole section, line "A" shows $9.5 \mathrm{~m} / \mathrm{min}$ (line " $\mathrm{B}$ " is $2.7 \mathrm{~m} / \mathrm{min}$ ). From our analysis, we feel confident that the TOC increases in the cased hole from 26:06 (intersection of both line " $\mathrm{A}$ " and "B"). Despite the artificial temporal lag of line "A" to match line "B" at the $133 / 8$ " casing shoe, the projected final TOC after primary cementing is still too high for line "A" to allow for the top-up cement to fit the annulus. This indicates that cement slurry continues to sag into the open-hole section in the period where the TOC increases in the cased hole section.

After the pressure reaches a maximum of 75 bar when the TOC reaches the shoe of the $133 / 8$ " casing, it decreases back to 57 bar. The gradual decrease coincides with a temperature increase within the annulus which is likely caused by the latent heat of hydration of the cement. The pressure decrease can either be attributed to the setting of the cement or a gradual sagging of part of the cement to below the pressure gauge, opening a hydraulic connection to the formation. While the CBL shows homogeneous values between the shoe of the 13 3/8" casing and the pressure gauge, it is assumed that the cement does not further sag down in the annulus. This is also supported by the fact that there is no vertical temperature perturbation observed below the shoe after 26:00. The theory of free-falling cement blobs is further confirmed by the comparison of calculated velocity with the velocities that were interpreted from the DTS data. The fiber optic cable is in direct contact with the pumped fluids in the well annulus. The cable mantle material is stain-less steel with a high thermal conductivity. Therefore, we assume an almost instantaneous thermal effect on the temperature sensing glass fiber upon a temperature change caused by the moving fluid front. The simple modeling approach predicted a velocity within the observed order-of-magnitude, which is almost 
two order-of-magnitudes greater than what would be expected from the injection of a homogeneous cement plug in the annulus.

\section{Impact on the outcome of the cementing operation}

From the CBL log evaluation we conclude a low cement bond. We interpret the low cement bond as a result of a non-optimal placement of cement slurry (e.g., dilution, free-falling of cement blobs). Analyzing the DTS temperature data acquired during the cementing operation in combination with the thermo-electrical sensors allowed to reveal some of the governing hydraulic processes. Not only did the analysis show that the limited flow rate led to a free fall of cement blobs within the annulus, it could also be shown that dilution of cement occurred that led to a dilution of the cement slurry which corresponds not only to a low CBL reading but also to the analysis of the TOC together with the pressure readings within the annulus.

It is important to mention that there is a risk that the pressure gauge was malfunctioning and that the recorded values do not display the actual downhole pressure conditions. The calibration or restriction to protect the gauge could also be affecting the read-out. The damage on TC3 which was observed during run-in-hole of the casing also imposes the risk that the temperature reading is incorrect.

\section{Conclusions}

For the first time, a reverse cementing job in a high-temperature geothermal well could be monitored and analyzed using a combination of permanently installed distributed fiber optic and electronic sensors as well as conventional well logging equipment. Data from the permanently installed sensors were used to interpret the hydraulic situation during cement pumping and the initial phase of cement setting. Based on this analysis, CBL data from the uppermost $832 \mathrm{~m}$ could be interpreted with more confidence.

The low CBL reading in the depth interval below the 13 3/8" casing shoe is most likely related to the excessive amount of retarder. The amount of retarder was calculated based on the BHCT that did not consider the well cooling due to the loss of circulation. Nevertheless, the low CBL reading can additionally be attributed to the observed injectivity of water and cement into the formation which is pointed out by our analysis. We observe an inflow of fluid (or steam) from the formation at times where the pressure gauge reading drops below the static formation pressure both in the DTS temperatures and thermocouple data. The inflow of formation fluid dilutes the cement slurry and reduces its density. From our calculation based on pressure gauge and DTS data, each cubic meter of cement slurry was diluted with an additional $34 \%$ of water in the depth interval from 13 3/8" casing shoe (794 $\mathrm{m}$ below surface) and the pressure gauge (1232 $\mathrm{m}$ below surface). Moreover, we find evidence from the DTS temperatures, that at least $1.8 \mathrm{~m}^{3}$ of cement slurry was pumped into the formation just below the shoe of the $133 / 8$ " casing. This finding is partly based on a cooling effect below the casing shoe and partly based on the change of the general DTS pattern for depth intervals where cement is falling (vertical pattern) and depth intervals where the cement begins to settle (horizontal pattern). We interpret this pattern transition in the DTS data as the TOC.

Complementary to conventional monitoring data from cementing operations, fiber optic distributed temperature data can give valuable information about downhole 
processes in real-time. From the analysis done in this study, we find evidence that curing loss zones concurrently with cementing a long casing string might cause undesired results. The current practice of drilling blind, i.e., drilling with total circulation loss, as a standard procedure in high-temperature geothermal drilling should be reconsidered for such long cementing intervals. While drilling an interval with total circulation loss might be acceptable if no casing is planned to be cemented, drilling blind for an interval that should be cased and fully cemented needs to be carefully evaluated.

The experience gathered in Iceland from this work and from the longer-term emphasis on research targeting deeper understanding of the deep roots of geothermal energy harnessing, has been funded through both national efforts (GEORG 2020) and with support from European framework research programmes (Fridleifsson et al. 2017). This type of joint collaborative efforts involving research organizations, energy industry and energy agencies that collate and openly share results are needed to increase predictability and successful harnessing of geothermal energy.

\section{Abbreviations}

BHCT:: Bottom-hole-circulation-temperature; BHST:: Bottom-hole-static-temperature; bwoc:: By-weight-of-cement; Cal.x/ Cal.y:: Caliper log; CBL:: Cement-bond-log; DTS:: Distributed temperature sensing; IDDP:: Iceland Deep Drilling Project; II:: Injectivity index; KOP:: Kick-off-point; MD:: Measured depth; MM:: Multi-mode (fiber); OTDR:: Optical time domain reflectometry; PG:: Pressure gauge; PT logging:: Pressure and temperature logging; SM:: Single-mode (fiber); sk:: Sack, unit of measure for Portland cement; TC:: Thermocouple; TOC:: Top-of-cement; TD:: Total depth, maximum depth reached in the well.

\section{Acknowledgements}

The authors are thankful to Gudmundur Ómar Fridleifsson, Ómar Sigurdsson, as well as the staff from HS Orka for providing access to the well and well data and support during and after the field campaign. The authors are also thankful to the staff of Iceland Drilling for the support during the field campaign. This work would not have been possible without the continuous support from our colleagues at ISOR and GEORG Geothermal Research cluster. The authors would also like to thank Adrian Desmarais from Petrospec Engineering for the fruitful discussions on the data from the electric downhole gauges. The authors are also grateful to the reviewers for their thorough comments and suggestions to this manuscript.

\section{Authors' contributions}

MPL and TR planned the measurement campaign, collected the DTS data, interpreted the DTS data and analyzed the annular injectivity and static formation pressure. TBW performed the CBL log interpretation. SK provided the analysis on the cement droplet velocities in the annulus. AS provided data for the well drilling and completion and the cementing procedure. SGB managed the DEEPEGS project and commented on the final draft. All authors read and approved the final manuscript.

\section{Funding}

Open Access funding enabled and organized by Projekt DEAL. The research leading to these results has received funding from the European Union's Horizon 2020 research and innovation programme under grant agreement No. 654662 (Project GeoWell) and grant agreement No. 690771 (DEEPEGS). Also, this project has received funding from the European Union's Seventh Programme for research, technological development and demonstration under grant agreement No: 608553.

\section{Data availability statement}

The acquired fiber optic DTS data are freely available under the Creative Commons Attribution International 4.0 Licence (CC BY 4.0) by GFZ Data Services (Lipus and Reinsch 2020). Data from the temperature and pressure gauges are also freely available (Eggertsson and Stefánsson 2020).

\section{Competing interests}

The authors declare that they have no competing interests.

\section{Author details}

${ }^{1}$ GFZ German Research Centre for Geosciences, Telegrafenberg, 14473 Potsdam, Germany. ${ }^{2}$ Fraunhofer IEG, Fraunhofer Research Institution for Energy Infrastructures and Geothermal Systems IEG, Lennershofstrasse 140, 44801 Bochum, Germany. ${ }^{3}$ Iceland GeoSurvey (ISOR), Grensásvegur 9, 108 Reykjavík, Iceland. ${ }^{4}$ NORCE Norwegian Research Centre AS, Prof. Olav Hanssensvei 15, 4021 Stavanger, Norway. ${ }^{5}$ HS Orka hf, Svartsengi, 240 Grindavík, Iceland. ${ }^{6}$ GEORG Geothermal Research Cluster, Grensásvegur 9, 108 Reykjavík, Iceland.

\section{Appendix}


Table 4 Laboratory analysis of cement slurry (Part 1/2)

\begin{tabular}{|c|c|c|}
\hline Chemical & Concentration & Unit \\
\hline \multicolumn{3}{|l|}{ Chemical composition } \\
\hline Cement & 94.00 & $\mathrm{lb} / \mathrm{sk}$ \\
\hline Silica flour & 40.0 & $\%$ bwoc \\
\hline Retarder & 0.50 & $\%$ bwoc \\
\hline \multicolumn{3}{|l|}{ Calculations } \\
\hline Surface density & 16.2 & lb/gal \\
\hline Downhole density & 16.2 & lb/gal \\
\hline Sack weight & 94.00 & $\mathrm{lb} / \mathrm{sk}$ \\
\hline Dry weight & 132.07 & $\mathrm{lb} / \mathrm{sk}$ \\
\hline Dry yield & 1.55 & $\mathrm{ft} 3 / \mathrm{sk}$ \\
\hline Water & 5.87 & $\mathrm{gal} / \mathrm{sk}$ \\
\hline Total Fluids & 5.87 & $\mathrm{gal} / \mathrm{sk}$ \\
\hline Surface Yield & 1.49 & $\mathrm{ft} 3 / \mathrm{sk}$ \\
\hline Downhole Yield & 1.49 & $\mathrm{ft} 3 / \mathrm{sk}$ \\
\hline \multicolumn{3}{|l|}{ Conditions } \\
\hline Time to BHCT & 33 & $\min$ \\
\hline $\mathrm{BHCT}$ & 126.6 & ${ }^{\circ} \mathrm{C}$ \\
\hline BHST & 260 & ${ }^{\circ} \mathrm{C}$ \\
\hline Initial pressure & 459 & psi \\
\hline Final pressur & 3632 & psi \\
\hline Simulated depth & 6189 & $\mathrm{ft}$ \\
\hline
\end{tabular}

See Table 6 for unit conversion

Table 5 Laboratory analysis of cement slurry (Part 2/2)

\begin{tabular}{llll}
\hline Thickening time & \multicolumn{2}{l}{ Free fluids } \\
\hline $\begin{array}{l}\text { Bearden units of consistency } \\
\text { (bc) }\end{array}$ & Time & Surface $\left(21^{\circ} \mathrm{C}\right)$ & 0 \\
$19 \mathrm{bc}$ & $0: 00$ & Downhole $\left(82^{\circ} \mathrm{C}\right)$ & 0 \\
$40 \mathrm{bc}$ & $4: 32: 52$ & & \\
$50 \mathrm{bc}$ & $4: 34: 30$ & & \\
$60 \mathrm{bc}$ & $4: 35: 01$ & & \\
$70 \mathrm{bc}$ & $4: 35: 22$ & & \\
$99 \mathrm{bc}$ & $4: 38: 19$ & Downhole rheology & $\left(82^{\circ} \mathrm{C}\right)$ \\
Surface rheology & $\left(21^{\circ} \mathrm{C}\right)$ & $\mathrm{RPM}$ & Dial reading \\
RPM & Dial reading & 600 & 183.3 \\
600 & 302.2 & 300 & 113.8 \\
300 & 189.3 & 200 & 87.4 \\
200 & 135.6 & 100 & 54.8 \\
100 & 76.6 & 60 & 42.5 \\
60 & 50.9 & 30 & 36.3 \\
30 & 33.0 & 6 & 14.3 \\
6 & 18.2 & 3 & 15.1 \\
3 & 32.3 & PV & $83.7 \mathrm{CP}$ \\
PV & $144.1 \mathrm{CP}$ & YP & $24.6 \mathrm{lbf} / 100 \mathrm{ft}^{2}$ \\
YP & $28.5 \mathrm{lbf} / 100 \mathrm{ft}{ }^{2}$ &
\end{tabular}

The cementing contractor used a Fann Model 3530A to measure the rheological parameter 
Table 6 Conversion table from field unit to SI unit

\begin{tabular}{lll}
\hline Length & $1 \mathrm{ft}$ & $0.3048 \mathrm{~m}$ \\
Mass & $1 \mathrm{lb}$ & $0.453 \mathrm{~kg}$ \\
Volume & $100 \mathrm{gal}$ & $0.3785 \mathrm{~m}^{3}$ \\
& $100 \mathrm{ft}^{3}$ & $2.83 \mathrm{~m}^{3}$ \\
Density & $1 \mathrm{lb} / \mathrm{gal}$ & $119.8 \mathrm{~kg} / \mathrm{m}^{3}$ \\
Pressure & $1 \mathrm{psi}$ & $6894 \mathrm{~Pa}$ \\
& $100 \mathrm{~Pa}$ & $2.09 \mathrm{lbf} / \mathrm{ft}^{2}$ \\
Viscosity & $1 \mathrm{cP}$ & $1 \mathrm{mPa} \cdot \mathrm{s}$ \\
\hline
\end{tabular}

Received: 20 August 2020 Accepted: 22 January 2021

Published online: 18 February 2021

\section{References}

Allouche M, Guillot D, Hayman AJ, Butsch RJ, Morris CW. Well Cementing 2nd Edition. Schlumberger. 2006:562-563.

Teodoriu C, Falcone G. Comparing completion design in hydrocarbon and geothermal wells: The need to evaluate the integrity of casing connections subject to thermal stresses. Geothermics. 2009;38:238-46. https://doi.org/10.1016/j. geothermics.2008.11.006

Salim P, Amani M. Special considerations in cementing high pressure high temperature wells. International Journal of Engineering and Applied Sciences. 2012;1.https://doi.org/10.1007/978-94-009-9059-3

Bertani R, Büsing H, Buske S, Dini A, Hjelstuen M, Luchini M, et al. The first results of the Descramble project. In: Proceedings, 43rd workshop on geothermal reservoir engineering, Stanford University, Stanford, California. 2018.

Pálsson B, Hólmgeirsson S, Gudmundsson A, Bóasson HA, Ingason K, Sverrisson H, et al. Drilling of the well IDDP-1. Geothermics. 2014. https://doi.org/10.1016/j.geothermics.2013.08.010

Fridleifsson GÓ, Bogason S, Ingolfsson H, Vergnes P, Thorbjörnsson I, Peter-Borie M, et al. Deployment of deep enhanced geothermal systems for sustainable energy business. Strasbourg, France: European Geothermal Congress; 2016.

Ravi KM, Sutton DL. New rheological correlation for cement slurries as a function of temperature. SPE Annual Technical Conference and Exhibition. 1990.https://doi.org/10.2118/20449-MS

Bertini G, Giovannoni A, Stefani GC, Gianelli G, Puxeddu M, Squarci P. Deep Exploration in Larderello Field: Sasso 22 Drilling Venture. Advances in European Geothermal Research. 1980.https://doi.org/10.1007/978-94-009-9059-3

Fridleifsson GÓ, Elders WA, Albertsson A. The concept of the Iceland deep drilling project. Geothermics. 2014. https://doi. org/10.1016/j.geothermics.2013.03.004

Reinsch T, Dobson P, Huenges E, Poletto H, Sanjuan B. Utilizing supercritical geothermal systems: a review of past ventures and ongoing research activities. Geothermal Energy. 2017. https://doi.org/10.1186/s40517-017-0075-y

Hurtig E, Grosswig S, Jobmann M, Kühn K, Marschall P. Fibre-optic temperature measurements in shallow boreholes: experimental application for fluid logging. Geothermics. 1994;23. https://doi.org/10.1016/0375-6505(94)90030-2

Förster A, Schrötter J, Merriam DF, Blackwell DD. Application of optical-fiber temperature logging - an example in a sedimentary environment. Geophysics. 1997;62(4).https://doi.org/10.1190/1.1444211

Henninges J, Huenges E, Burkhardt $\mathrm{H}$. In situ thermal conductivity of gas-hydrate-bearing sediments of the Mallik 5L-38 well. Journal of Geophysical Research. 2005;110. https://doi.org/10.1029/2005JB003734

Carnahan BD, Clanton RW, Koehler KD, Harkins GO, Williams GR. Sensor Highway, Fiber Optic Temperature Monitoring Technology. SPE Western Regional Meeting held in Anchorage. 1999.

Patterson JR, Cardiff M, Coleman T, Wang H, Feigl KL, Akerley J, et al. Geothermal reservoir characterization using distributed temperature sensing at Brady Geothermal Field. The Leading Edge: Nevada; 2017. https://doi. org/10.1190/tle36121024a1.1

Pearce JG, Rambow FHK, Shroyer W, Huckabee P, deJongh H, Dria DE, et al. High Resolution, Real-Time Casing Strain Imaging for Reservoir and Well Integrity Monitoring: Demonstration of Monitoring Capability in a Field Installation. SPE Annual Technical Conference and Exhibition. 2009. https://doi.org/10.2118/124932-MS

Earles DM, Stoesz CW, Surveyor N, Pearce JG, DeJongh HA. Fiber Optic Strain Sensing at the Sand Face Enables RealTime Flow Monitoring and Compaction Mitigation in Openhole Applications. SPE Annual Technical Conference and Exhibition held in Denver, Colorado, USA. 2011.

Koelman JMVA, Lopez JL, Potters JHHM. Fiber Optic Technology for Reservoir Surveillance. Conference Proceedings, IPTC 2012:International Petroleum Technology Conference. 2012.

Reinsch T, Henninges J, Ásmundsson R. Thermal, mechanical and chemical influences on the performance of optical fibres for distributed temperature sensing in a hot geothermal well. Environmental Earth Science. 2013;70. https:// doi.org/10.1007/s12665-013-2248-8

Bücker C, Grosswig S. Distributed temperature sensing in the oil and gas industry - insights and perspectives. Oil Gas European Magazine. 2017;43:

Lipus M, Reinsch T, Schmidt-Hattenberger C, Henninges J, Reich M. Gravel Pack Monitoring With a Strain Sensing Fiber Optic Cable. Oil Gas European Magazine 4. 2018. https://doi.org/10.19225/181202 
Raab T, Reinsch T, Cifuentes SRA, Henninges J. Real-Time Well-Integrity Monitoring Using Fiber-Optic Distributed Acoustic Sensing. SPE Journal. 2019;24(05). https://doi.org/10.2118/195678-PA

Fridleifsson GÓ, Elders WA, Zierenberg RA, Stefánsson A, Fowler APG, Weisenberger TB, et al. The Iceland Deep Drilling Project $4.5 \mathrm{~km}$ deep well, IDDP-2, in the seawater-recharged Reykjanes geothermal field in SW Iceland has successfully reached its supercritical target. Scientific Drilling. 2017;23:1-12. https://doi.org/10.5194/sd-23-1-2017

Jónsson SS, Sigurgeirsson MÁ, Sigurdsson Ó, Ingólfsson H. Reykjanes - Hola RN-15. 3. áfangi: Borun vinnsluhluta frá $804 \mathrm{~m}$ i 2507 m dypi. Iceland GeoSurvey, ÍSOR-2010/050 (in Icelandic). Report. 2010.

Stefánsson A, Gíslason T, Sigurdsson O, Fridleifsson GO. The Drilling of RN-15/IDDP-2 Research Well at Reykjanes in SW Iceland. GRC Transactions. 2017:41.

IDDP. IDDP-2 Way Forward Workshop (WFW), Report of Workshop No. 11 of the Iceland Deep Drilling Project, 23 March 2018. https://iddpis/wp-content/uploads/2018/04/Way-Forward-Workshop-20-21-March-2018-SAGA-REPORT-No-11 pdf. 2018.

Stefánsson A, Fridleifsson GÓ, Sigurdsson Ó, Gíslason T. The IDDP-2 DEEPEGS Drilling Experience and Lesson Learned. Proceedings World Geothermal Congress 2020. 2020.

Founargiotakis K, Kellessidis VC, Maglione R. Laminar, Transitional and Turbulent Flow of Herschel-Bulkley Fluids in Concentric Annulus. The Canadian Journal of Chemical Engineering. 2008;86. https://doi.org/10.1002/cjce.20074

Hartog AH. A Distributed Temperature Sensor Based on Liquid-Core Optical Fibers. Journal of Lightwave Technology. 1983. https://doi.org/10.1109/JLT.1983.1072146

GEORG. Legacy of project results, publications; : visited by Internet (https://georgclusteris/publications/), October 2020. 2020. Lipus M, Reinsch T. Data from distributed temperature sensing (DTS) measured along a fiber optic cable permanently installed behind casing in well RN-15/DEEPEGS/IDDP-2. GFZ Data Services: Iceland; 2020. https://doi.org/10.5880/ GFZ.6.2.2018.0

Eggertsson GH, Stefánsson A. Temperature and pressure data from permanently installed sensors behind casing in well RN-15/DEEPEGS/IDDP-2. GFZ Data Services: Iceland; 2020. https://doi.org/10.5880/GFZ.4.8.2020.004

\section{Publisher's Note}

Springer Nature remains neutral with regard to jurisdictional claims in published maps and institutional affiliations.

\section{Submit your manuscript to a SpringerOpen ${ }^{\circ}$ journal and benefit from:}

- Convenient online submission

- Rigorous peer review

Open access: articles freely available online

- High visibility within the field

- Retaining the copyright to your article

Submit your next manuscript at $\boldsymbol{\nabla}$ springeropen.com 